\title{
ORAL DELIVERY OF SILVER NANOPARTICLES - A REVIEW
}

\author{
VEDAMURTHY JOSHI ${ }^{1 *}$, FIRDOS SULTHANA ${ }^{1}$, DINESHA RAMADAS ${ }^{2}$
}

${ }^{1}$ Department of Pharmaceutics, CORMIL and CMPAT, Sri Adichunchanagiri College of Pharmacy, Adichunchanagiri University, Javarana Hally, Karnataka, India. ${ }^{2}$ Department of CORMIL and CMPAT, Sri Adichunchanagiri College of Pharmacy, Adichunchanagiri University, Javarana Hally, Karnataka, India. Email: vedamurthyjoshi@gmail.com

Received: 10 August 2021, Revised and Accepted: 24 September 2021

\begin{abstract}
Silver nanoparticles (NP) offer many applications in the science and technology. Oral delivery of such tiny particles results in enhanced drug absorption, reduction in dose, and minimize adverse effects. This review focuses on the mainly on the effects in the gastrointestinal tract along with its in vitro and in vivo studies carried on the silver NP. In this review, we compiled some of the extensive research in the field of silver NP, highlighting some of the most recent trends in the area. Search was carried in English language using Science direct, PubMed, and Google scholar search engines. The effects of silver NP on gastrointestinal tract such as absorption, distribution, metabolism, and elimination were compiled in this review. In addition, selected in vitro and in vivo studies related to the same are discussed. The accumulation of silver NP leading to Arginia condition also emphasized in the study. Silver NP and herbal silver NP in oral delivery can be exploited for the further safer and effective treatment.
\end{abstract}

Keywords: Nanoparticles, Herbs, Silver, Gastrointestine, Drug absorption, Arginia.

(C) 2021 The Authors. Published by Innovare Academic Sciences Pvt Ltd. This is an open access article under the CC BY license (http://creativecommons.org/ licenses/by/4.0/) DOI: http://dx.doi.org/10.22159/ajpcr.2021v14i11.42986. Journal homepage: https://innovareacademics.in/journals/index.php/ajpcr

\section{INTRODUCTION}

Oral drug administration has got several benefits over other routes of administration. This route is non-invasive, safer, comfortable, do not require skilled person to administer, dose adjustment can be tailor made to suit individual patient and hence it is most patient compliant. Despite of these facts, oral drug delivery posses' big challenges to gain efficient therapeutic results, this is due to the multitude of biological barriers that are present at some point of the gastrointestinal (GI) tract that a drug carrier ought to navigate through [1]. Some of enzymes present in drug delivery biological path inside the stomach having strong acidic $\mathrm{pH}$ environment, which degrade the capsules to useless, and results in the inefficient penetration of medication across GI tissue obstacles, into systemic move, the eventual clearance of medication through the GI tract, which can also occur prior to drug release [2]. To overcome these barriers, the delivered dosage of medication is often more than required therapeutically. However, it is far vital that the drug concentration need not exceed the level that could motive toxicity within the body, as has been observed with a few DNA and protein based totally drugs above critical concentrations. On the other hand, if a drug at a non-toxic awareness level passes the physiological barriers of the GI tract, its delivered dosage may not be effective [3].

\section{NANO PARTICLES (NP)}

NP are known as colloidal system made from solid polymers that may be classified with their length and practice processes. They are smaller than $1 \mu \mathrm{m}$ (submicronic particles) and the objects ranging in length ranging 1-100 $\mathrm{nm}$, that due to their size may additionally fluctuate from the bulk material [4]. Nanosized inorganic particles are of both easy or complicated nature, show particular physical and chemical properties [5]. NPs have drawn increasing interest from each department of medication for their capacity to supply drugs in the ultimate dosage range regularly resulting in multiplied healing performance of the pills, weakened side outcomes, and improved patient compliance [6]. NP have a large surface location to volume ratio, which allows them to soak up excessive portions of drugs and to be unfold without problems at some stage in the bloodstream [7]. Nanotechnology is anticipated to have an impact on medication. The utility of the technology used for analysis, treatment, tracking, and manipulate of biological systems is now frequently called nano-medicine. In medicine, the usage of numerous nanomaterials as pharmaceutical delivery structures for drugs, DNA, and imaging agents has gained growing interest. NPs showed characteristic colors and properties with the variation of size and shape, which can be utilized in bioimaging applications [8]. Encapsulation in a NP may added partly defend the contents from the degrading surroundings within the stomach and GI tract but peristalsis appreciably limits their retention. Bioavailability of NP-mediated oral delivery subsequently poor and optimization is needed, permitting adequate space for improvement [9].

\section{METALLIC NP}

Metallic NPs are in basic terms manufactured from the metals precursors. Because of Localized Surface Plasmon Resonance characteristics, these NPs own specific optoelectrical homes. NPs of the alkali and noble metals, that is, $\mathrm{Cu}, \mathrm{Ag}$, and $\mathrm{Au}$ have a vast absorption band in the visible region of the electromagnetic solar spectrum [10]. The facet, length, and shape controlled synthesis of steel NPs is crucial in contemporary substances. Due to their superior optical properties, metallic NPs locate applications in lots of research areas [11].

\section{SILVER NP}

Silver NP (Ag-NPs or Nano-Silver) have attracted increasing interest due to their unique bodily, chemical, and biological properties as compared to their macro-scaled opposite numbers [12]. Silver ions $(\mathrm{Ag}+)$ are dissociated from distinct salts and from particulate silver, Ag-NPs have exceptional physical chemical properties, including a excessive electrical and thermal conductivity, Raman scattering, the lowest melting and boiling points, chemical stability, catalytic hobby, and non-linear optical behavior [13]. Moreover, silver is the maximum reactive of the "noble" metals, and its cations exert poisonous results against numerous microorganisms. Silver in shape of NPs discovered even extra specific houses, which permits them to be applied inside in a couple of fields of method and medicinal drug: solar electricity harvesting [14]. The suspensions of silver NP of nano-length or more is natural in concept, but in practice be the combinations of silver ions, medium sized NP and excited NP. Silver NP are one of the most attractive nanomaterials for commercialization applications. 


\section{SYNTHESIS OF SILVER NP}

Different methods such as organic synthesis, chemical, and physical, the AgNPs are obtained. The method of chemical reduction of silver salts is the common method following in the synthesis of AgNPs. Among silver salts, silver nitrate is very often used due to its cost and strong chemical properties. When silver nitrate is reduced to AgNPs, due to reduction response, brown color appears and with the reluctant such as hydrogen, citrate, and borohydride [15].

In the above case, without decomposition of AgNPs, borohydride acts as a strong reducing agent, also reduces the size of NPs when compared to glucose. The other biological method to synthesize AgNPs is Green synthesis in which as reducing and stabilizing agent sodium alginate is used [15].

Due to the instability nature of AgNPs, it always obtained at low yield. The aggregation and oxidation are the two factors used to determine the stability of AgNPs. Hence, capping agents such as surfactants with ligands, polymers with functional groups such as polyvinylpyrrolidone, polyethylene glycol and polymethyl methacrylate are used to increase the stability of AgNPs. [15]. Plant sources such as leaves of aloevera, Citrullus colocynthis, Ocimum sanctum, Cinnamomum camphora, and geranium are used to synthesize NPs. Herein, the authors synthesized the NPs by green synthesis technology by incorporating curcumin from Curcuma longa as natural reducing agent [16].

\section{PREPARATION OF NP}

For the preparation of NP, the choice of the appropriate method is based totally at the drug to be loaded and physicochemical properties of the polymer. The primary preparation method of NP consists of:

a. Emulsion-Solvent Evaporation Method

b. Double Emulsion and Evaporation Method

c. Salting Out Method

d. Emulsion Diffusion Method

e. Solvent Displacement/Precipitation Method [17].

\section{GI TRACT}

To incorporate the NPs in GI tract, two important methods are there, they are, exogenous, and endogenous. It was reported that, in endogenous method, the NPs resources are calcium and phosphate secretion of gut. In exogenous method, NPs sources are food, water, cosmetics, and pharmaceuticals [18]. In food industries especially in the preparation of sauce, dressings, the titanium dioxide, silicates, or alumina-silicates are widely used. The above said type of NP of spherical in shape and approximate size $100 \mathrm{~nm}$ is showed resistivity to degradation. The NP known as endogenous particles such as calcium and phosphorous which are re-circulate inside the gut environment [18] and also the skin, lungs and GI tract are considered as the major routes of NP [19]. The routine way of entering into the GI tract is nutritional micro and NP. The advanced nano-technology techniques improved the customized NP based drugs for more absorption in the GI tract [20]. Other than the above said methods, NP may enter into the GI tract by various methods such as ingested using food, water, drugs and cosmetics, and inhalation [20]. If the particle size is much smaller, it can effortlessly diffuse within the GI secretions and join the blood flow and translocate [20].

It is one of the critical tasks for the uptake or ingestion of particles and molecules in GI. Oral drug transport systems are having more complicated barrier-exchange systems for insertion and transport of molecules and their absorption inside the intestine. The oral drug delivery system is more tough and complicated because of low solubility, low apparent permeability, and low bioavailability by means oral chemotherapy [21]. Nanotechnology enables the researchers/scientists to monitor out the barriers of conventional path procedures and is feasible to supply the focused hydrophobic, precise drugs to particular regions of GI tract; transcytosis of medication and intracellular transport of drugs [22].

\section{BARRIERS TO ORAL DELIVERY OF NPS}

For oral transport of NPs, factors such as acid media of GI tract, GI environment, digestive enzymes, and tight enzymes are considered as barriers. The gradual increase or change of $\mathrm{pH}$ range in stomach, intestine is also acts as barriers for NPs. This varied pH inside the GI tract makes tough to keep NP integrity during its stay and journey. The stomach consists of strong hydrochloric acid and enzyme pepsin, which plays a big role in degrade of proteins [23]. The duodenum of the small gut contains bile salts and degradative enzymes, play a powerful role in degrade/breakdown starch, fat, and proteins, respectively. Other bodily contents such as pancreatic juices comprising pancreatin, trypsin, lipase, peptidases (breaks peptide bonds), and maltase (degrades maltose) helps in breakdown of NPs. All of these degradative enzymes present bold boundaries for the oral delivery of proteins, nucleic acids, or drugs [24].

The mucus layer that traces the surface of the GI tract can gift every other barrier to delivery and also in speedy NP clearance. However, a few NP are provided an effort to open the tight junctions and enhance delivery which is useful in keeping shipment integrity due to the lack of proteolytic encounters when shipping occurs through the tight junctions [25].

\section{OVERCOMING ORAL DELIVERY BARRIERS WITH USE OF NP}

Using NP, one can protect drug, peptide, or nucleic acid contents from degradative enzymes, accelerated mucoadhesion, and extended retention within the GI tract. It also enhancing the oral delivery of poorly adsorbed tablets, proteins, and nucleotides by increasing the interaction period with the mucus layer of the intestine [26]. It is understood that the elevated mucosal interplay is because of positively charged NP and the negatively charged mucus electrostatic interactions and endothelial layer [27]. It was reported that, NPs have mucoadhesive houses by the usage of mucoadhesive polymers, which includes Eudragit, poly(acrylic acid), sodium alginate, chitosan, and the like [28]. Although the mucoadhesive properties of NPs are beneficial, it end up relation if loosely connected mucus layer that is unexpectedly shed using the stomach. By engineering, we can mask the cargo nature and enhance the delivery shipment through each of the cellular membrane such as epithelial layer by altering the size, rate, and other qualities of the NP [29].

\section{ABSORPTION, DISTRIBUTION, METABOLISM, AND EXCRETION (ADME)}

\section{Absorption}

The absorption while in oral administration both in human and different mammals has been defined qualitatively in various investigations. Few studies providing statistics regarding quantitative analysis are used to analyze the orally administered radionuclide of silver (as silver nitrate) and silver excretion in numerous species [30]. The following are the fecal excretion values such as $99.6 \%$ for mice, $98 \%$ for rats, $90 \%$ for puppies, and $94 \%$ for monkeys. Silver can be absorbed after excreted through the bile, and the information suggest that absorption ranges from $0.4 \%$ to $10 \%$ depending at the species, such as $10 \%$ and $6 \%$ for dogs and monkeys, respectively [31]. It was investigated and reported that, silver retention in a 43-year vintage female orally administered with Silver NP, who already suffered from argyria, with the usage of a radioactive tracer, silver retention turned into observed to be $18 \%$. While comparing ionic silver and nanoparticulate silver after oral administration, the latter become shown to be less bioavailable based totally on better fecal excretion and lower absolute levels in organs following head to head investigations [32].

\section{Distribution}

The ionic and nanoparticulate silver which are orally administered had been deposited in a huge range of organs. The maximum nicely defined depositional impact is the blue-grey discoloration of the human pores and skin that is observed at some point of argyria [33]. In addition 
to pores and skin, silver deposition has also been detected in several organs during oral administration, such as liver, kidneys, brain, pores and skin, spleen, pelt, eyes, blood, small intestine, muscular tissues, stomach, bladder, lungs, tongue, prostate, teeth, thyroid, parathyroid, coronary heart, salivary gland, duodenum, and pancreas and in the kidneys, it is deposited inside the glomerular basement membrane. In the oral administration of Silver NPs, silver does cross the blood-brain barrier to enter the brain extracellular fluid; however, it is deposited in its lining [34]. It was reported that, in the brain of a 72 year-old woman silver is stricken by Argyria, but, no silver was located inside the central nervous parenchyma and determined the switch of silver from mothers to offspring following an oral dose of $250 \mathrm{mg} / \mathrm{kg}$ of bw/day of $8 \mathrm{~nm}$ silver NP, suggesting that silver can move the placental barrier [35]. In other studies, the oral administration of $14 \mathrm{~nm}$ silver NP at an equivalent dose resulted in a similar pattern of distribution, despite the fact that lower amounts have been found inside the lungs, muscle, plasma, and brain compared to ionic silver [36].

In comparison an oral dose of $9 \mathrm{mg}$ of ionic silver/kg of bw/day (as silver nitrate) with an oral dose of $90 \mathrm{mg}$ of nanoparticulate silver $/ \mathrm{kg}$ of bw/day for 28 days (the NP sizes had been 15 and $20 \mathrm{~nm}$ ), and noticed similar outcomes [36].

\section{Metabolism}

It has been reported that, silver particles can be deposited at pores of tissues and skin epidermis, glomeruli and in intestine. In vivo studies showed that, the debris of the rat intestine contains silver along with selenium and sulfur and the diameter of the debris is $12 \mathrm{~nm}$ [37]. It was reported that, the silver particles comprise selenium deposited in human Argyria. It was noticed that, the silver particle noticeable deposition both in quantity and length in rat eyes for the duration of the primary weeks of administration. It was also reported that, after withdrawn of silver for about 12 months, it was noticed that the length of silver NP is reduced. It has been reported that, the ionic silver or silver present in the suspension is being deposited but not the whole particle's being deposited [38].

\section{Excretion}

\section{Fecal excretion}

In fecal excretion rate of silver particles was studied in which, the usage of the one hundred ten radionuclide of silver in several animal species, has discovered and reported the fecal excretion rates, which are $99.6 \%$ for mice, $98 \%$ for rats, $90 \%$ for dogs, and $98 \%$ for monkeys. In oral and non-oral administration bile duct studies, due to silver accumulation in liver, the excretion of the absorbed silver was faded and whereas non-oral investigation it was reported that $50 \%$ of an infused dose of silver can be recovered inside the rat bile [39]. It shows that, oral administration is better for $14 \mathrm{~nm}$ silver NP than for ionic silver; namely, $63 \%$ and $49 \%$ for NP and ionic silver. This explains the lower bioavailability of silver NP [40].

\section{Urinary excretion}

The urinary excretion at $12 \mathrm{~h}$ in a woman turned into within the range of $2-4,104 \%$ of an orally administered dose of a radioactive silver tracer, a constrained amount of the orally administered 110 radionuclide of silver became excreted in the urine. The urinary fecal excretion ratios were such as 0.001 (mice), 0.001 (rats), 0.019-0.26 (monkeys)m and $0.012-0.061$ (dogs). About $0.012 \%$ and $0.057 \%$ of administered silver within the urine following the oral administration of $14 \mathrm{~nm}$ silver NP and silver acetate [41]. The detected silver inside the rat urine following the oral administration of $1 \mathrm{mg} / \mathrm{kg}$ of bw of $8 \mathrm{~nm}$ particles, specifically $0.042 \mathrm{lg} / \mathrm{mL}$ (on this investigation, $378 \mathrm{lg} / \mathrm{g}$ become determined in the feces) [41].

\section{EFFECT OF SILVER ON BODY WEIGHT}

The reports says that, the administration of Silver NPs will retard the growth rates in rat model it was administered a $0.25 \%$ silver nitrate solution for $81 / 2$ months (this dose corresponds to $81 \mathrm{mg} / \mathrm{kg}$ of BW/day), when silver administration was withdrawn, the body weight became reinstated by a period of 10 weeks. Similar type of report noticed in other studies where for the source of silver NP, silver acetate used and administered ( $9 \mathrm{mg}$ of $\mathrm{Ag} / \mathrm{kg}$ of bw/day) and also in another 13 week study of the oral management of $500 \mathrm{mg}$ of $60 \mathrm{~nm} \mathrm{AgNPs} / \mathrm{kg}$ of bw/day in rats, showed reduced body weight male mice [42].

\section{EFFECT OF SILVER ON GI TRACT}

There are three investigations reports during oral toxicity studies that, inside the GI tract they noticed excessive silver deposition where AgNPs (of size 5-20 nm) broken the epithelial cellular microvilli and intestinal glands after administration for 21 days in mice model [43].

\section{IN VITRO AND IN VIVO STUDIES OF ORAL NANOCARRIERS}

\section{In vitro studies}

In the development of advanced pharmaceutical pills, the preclinical toxicology assessment is an essential step. Before administration of drugs to human beings, toxicology study by the way of in vitro and in vivo methods so as to make sure the safety of medicaments. Till date, the NPs designed for oral delivery purposes studies performed were focused on the basis of their functionality via the epithelial membrane and promote their efficacy. In many instances, the intestinal membrane permeability alterations involved in potential accumulation of the nanocarriers inside the body and other consequences were underestimated. In many cases, only in vitro tests had been done to examine the toxicity of the nano-carrier. In NPs toxicity studies in in vitro models are insufficient to guess all possible dangers to human beings and to avoid, a carry of hit transition through clinical trials is much required [44]. To analyze the nano-toxicity of the nano-carriers a consequent in vitro and in vivo studies are required and researchers are recommending the same.

\section{Cytotoxicity studies}

In vitro assays based totally on cell way of studies, where very successful methods are established to conduct on cells of an organism, which are very useful in the screening of NPs and in mechanistic assays.

\section{Cell models}

Ideally, using required cell lines related to the target organs is used for in vitro studies. For the examination of nano carriers toxicity during oral drug delivery carried out in human mobile strains such as enterocytes, metabolic activities. Human colon carcinoma derived Caco- 2 cells were used as a model of intestinal epithelium to examine the toxicity of many NPs [45]. The cells may co-cultured with HT29 which is additionally derived from human colon carcinoma while developing post confluent. These models do the evaluation of mucosa changes in the gel like structure. As an option, using primary cultured cells used to avoid mobile culture protocols during toxicity assays [46].

\section{In vivo studies}

In recent years, even the in vitro models giving feasible information which are sufficient in expecting possible risks to humans and to justify transition through scientific trials before releasing into the market. In vitro results provide statistics and not represent very realistic version of the way of NPs will engage with a particular organ of the body. For instance, in vitro assays will not reveal enough information about the toxic nature of NPs and hence not be good enough for figuring out the toxic ability. Consequently, information acquired for in vitro studies a final verification required in vivo experiments to assess nano-toxicity [47].

As per moral considerations, in vivo studies will do only at final stage for confirmation of its nano-toxic or nano-nontoxic nature of NPs because of the use and sacrifice of animals. Furthermore, these research studies needs long-term consequences, bio-distribution, tissue accumulation, and retention/excretion of NPs in a greater way than the in vitro models. There are number of interconnected pathways to understand in human situation and a single in vitro test cannot reveal everything. Toxicity exams are classified into acute, sub-acute, sub-chronic, and 
continual research. Other factors such as ADME and pharmacokinetics, carcinogenic and teratogenic studies are also much required for nanomaterial toxicity [48].

To conduct in vivo research it's essential to understand the overall conduct that NPs have to showcase within the organism: (a) route of management, (b) targeting and biodistribution residences after administration, (c) biodegradation path methods, and (d) eventual accumulation in the body. Hence, the knowledge of the physicochemical properties of nanocarriers will help in planning for the toxicological study [49].

In general, in vivo studies are undertaken in rodents, but in exceptional cases, studies with both zebrafish (Danio rerio) or Caenorhabditis elegans are also emerged as promising in vivo models for nanotoxicity research [50,51]. In vivo NPs toxicity research performed in rodents generally focused on (a) clinical signs and symptoms of toxicity, (b) adjustments in organ and tissue morphology, examined beneath microscopy, (c) changes in blood serum chemistry and cellular population, and (d) the general NP bio-distribution [52]. During in vitro research, before initiating the studies, consider many factors such as NP characterization and desire of the relevant model system. For in vivo research, great variant can be delivered because of species, pressure, weight loss plan, housing conditions, circadian rhythm variations, and endogenous microbiota. To analyze histological or serum/hematological adjustments, one must remember problems of exposure direction, NP dosing and precise tissue/organ or protein/cell type of interest. In the in vivo toxicity studies, it is crucial to confine with purity of nanomaterials and also any non-precise toxicity attributed to material impurities or organic contaminations may be excluded [53].

As we aware that, majority of nanotoxicity studies has focused on cell culture systems, includes complexity of the assays, the cost and the low throughput in comparison with the in vitro ones. Standardized protocols are also had to perform the in vivo research [54,55].

\section{Toxicity studies}

The study of effect of Ag-NPs on human health and environment a very less studies have been done though the above NPs are having a huge number of applications. Only few research articles are trying to enlighten regarding both in vitro and in vivo NP toxicity studies which includes consequences, cytotoxic nature, genotoxic effect in relevance to the size, length, concentration, time of exposure, and environmental elements [56]. Researchers noticed that, the unstable nature of NPs in media when it acts or combine with biological macromolecules/inorganic molecules/natural ions is due to the surface coating agents, amino acids, acetyl trimethyl ammonium bromide, citric acid, and sodium dodecyl sulfate are non-covalently attached to the nanosilver particles. Many in vivo and in vitro are also shown the toxic nature of AgNPs in certain model systems [57]. The whole toxicological investigations was done on the basis of the NPs length, shape, surface charge chemical composition, solubility, their capability to bind and affect organic sites as well as their metabolism and excretion influence. Although studies have done, still it is not very clear that, which degree the toxicity of AgNPs consequences from released silver ions and kind of toxicity is associated with the AgNPs consistent per se. Many authors opined that the measured silver ion content of the AgNP suspension not completely provide an explanation for the toxicity of the AgNP suspension $[58,59]$.

\section{SAFETY OF ORALLY DELIVERED NP}

It has been observed an exponential growth in the number of research publications about the toxicity of nanomaterials in the recent years. However, it remains difficult to come to conclusion by considering the others observation about NPs and the potential toxicity of nanomaterials. The other factors are the different methodologies, subjects, models are also under considerations. The International research for Standardization Organization (ISO) has posted several requirements which might be relevant for the category of engineered nanomaterials. As an instance, ISO/TS 107868:2011 describes the characterization of single-walled carbon nano-tubes (SWCNT) using UV-Vis, and ISO/TS 10798:2011 describes the characterization of SWCNT using Scanning Electron Microscopy and dispersive X-ray spectrometry evaluation (www. iso.org). Greater requirements for the characterization of the physicochemical properties of nanomaterials will appear and consequently permit the contrast and category of nanomaterials to be studied.

However, nano-metrology becomes a complicated dynamic nano-scale structures common in nanomedicine such as liposomes and polymerprimarily based micellar entities. Other applicable kinds are drug delivery agents that release their cargo of medication [60-62]. Before drive the NPs, it is mandatory to outline the bodily traits and numerous more strategies have to be implemented to correctly describe length and shape. It is reported that the propensity for aggregation might also alternate in exceptional solutions including cellular media without or with serum and inside the blood stream, and aggregation could have a substantial impact on NP toxicity and in vivo clearance mechanisms [63].

Regarding the safety evaluation of nanomedicine, the Nanotechnology Characterization Laboratory has provided protocols (www.ncl.most cancers.gov). Those assays function needs minimal requirements for physicochemical characterization and additionally need wellcharacterized reference materials [64]. One such reference is the citrate-stabilized gold NP from the National Institute of Standards and Technology (NIST). Current studies at NIST (www.nist.gov) are directed at producing reference standards for titanium dioxide and silver NP. Glaringly the strong, relevant, and synthetically reliable NP are taken into consideration as reference materials; also, medically applicable reference standards are required. It's crucial to underscore the presence of chemical residues such as catalysts or surfactants that provide fake results in toxicity research of nanomaterials [65].

\section{CONCLUSION}

The review study provides a detailed information about silver NP about its oral administration, which enlightens the exceptional strategies using to examine oral delivery of NP, barriers, toxicity, and safety. This survey study provides in different model systems like in vitro and in vivo studies, cell models and also its toxicity studies.

\section{ACKNOWLEDGMENT}

The authors gratefully acknowledge Vision Group of Science and Technology (VGST), Karnataka and Sri Adichunchanagiri College of Pharmacy, Adichunchanagiri University B.G. Nagara for all the support provided.

\section{AUTHORS' CONTRIBUTIONS}

We hereby declare that, all the authors contributed equally in preparing and finalizing this review manuscript.

\section{CONFLICT OF INTEREST}

The authors declare no conflict of interest.

\section{FUNDING}

This study was done with the financial support of VGST, Karnataka.

\section{REFERENCES}

1. Ojer P, Iglesias T, Azqueta A, Irache JM, López De Cerain A. Toxicity evaluation of nano-carriers for the oral delivery of macromolecular drugs. Eur J Pharm Biopharm 2015;97:206-17.

2. Ahadian S, Finbloom JA, Mofidfar M, Diltemiz SE, Nasrollahi F, Davoodi E. Micro and nanoscale technologies in oral drug delivery. Adv Drug Deliv Rev 2020;157:37-62.

3. Lam JK, Xu Y, Worsley A, Wong IC. Oral transmucosal drug delivery for pediatric use. Adv Drug Deliv Rev 2014;73:50-62.

4. Su Y, Ashworth V, Kim C, Adeleye AS, Rolshausen P, Roper C, et al. 
Delivery, uptake, fate, and transport of engineered nanoparticles in plants: A critical review and data analysis. Environ Sci Nano 2019;6:2311-31.

5. Mirzaei H, Darroudi M. Zinc oxide nanoparticles: Biological synthesis and biomedical applications. Ceram Int 2017;43:907-14.

6. Blasi P, Schoubben A, Giovagnoli S, Rossi C, Ricci M. Fighting tuberculosis: Old drugs, new formulations. Exp Opin Drug Deliv 2009;6:977-93.

7. Nel AE, Mädler L, Velegol D, Xia T, Hoek EM, Somasundaran P, et al. Understanding biophysico chemical interactions at the nano-bio interface. Nat Mater 2009;8:543-57.

8. Ray PC. Size and shape dependent second order nonlinear optical properties of nanomaterials and their application in biological and chemical sensing. Chem Rev 2010;110:5332-65.

9. Wu Z, Li T. Nanoparticle-mediated cytoplasmic delivery of messenger RNA vaccines: Challenges and future perspectives. Pharm Res 2021;3:1-6.

10. Henzie J, Lee J, Lee MH, Hasan W, Odom TW. Nanofabrication of plasmonic structures. Ann Rev Phys Chem 2009;31:60.

11. Chen A, Holt-Hindle P. Platinum-based nanostructured materials: Synthesis, properties, and applications. Chem Rev 2010;110:3767-804.

12. Jeong L, Park WH. Preparation and characterization of gelatin nanofibers containing silver nanoparticles. Int J Mol Sci 2014;15:6857-79.

13. Hernández WY, Lopez-Gonzalez D, Ntais S, Zhao C, Boréave A, Vernoux P. Silver-modified manganite and ferrite perovskites for catalyzed gasoline particulate filters. Appl Catal B Environ 2018;226:202-12.

14. Sakamoto JH, van de Ven AL, Godin B, Blanco E, Serda RE, Grattoni A, et al. Enabling individualized therapy through nanotechnology. Pharmacol Res 2010;62:57-89.

15. Tolaymat TM, El Badawy AM, Genaidy A, Scheckel KG, Luxton TP, Suidan M. An evidence-based environmental perspective of manufactured silver nanoparticle in syntheses and applications: A systematic review and critical appraisal of peer-reviewed scientific papers. Sci Total Environ 2010;408:999-1006.

16. Akhtar MS, Panwar J, Yun YS. Biogenic synthesis of metallic nanoparticles by plant extracts. ACS Sustain Chem Eng 2013;1:591-602.

17. Ribeiro HS, Chu BS, Ichikawa S, Nakajima M. Preparation of nanodispersions containing $\beta$-carotene by solvent displacement method. Food Hydrocoll 2008;22:12-7.

18. Moreno E, Schwartz J, Fernandez C, Sanmartin C, Nguewa P, Irache JM, et al. Nanoparticles as multifunctional devices for the topical treatment of cutaneous leishmaniasis. Exp Opin Drug Deliv 2014;11:579-97.

19. Elsaesser A, Howard CV. Toxicology of nanoparticles. Adv Drug Deliv Rev 2012;64:129-37.

20. Sekhon BS. Food nanotechnology-an overview. Nanotechnol Sci Appl 2010;3:1.

21. Chakraborty S, Shukla D, Mishra B, Singh S. Lipid-an emerging platform for oral delivery of drugs with poor bioavailability. Eur J Pharm Biopharm 2009;73:1-5.

22. Patra JK, Das G, Fraceto LF, Campos EV, del Pilar Rodriguez-Torres M, Acosta-Torres LS, et al. Nano based drug delivery systems: Recent developments and future prospects. J Nanobiotechnol 2018;16:1-33.

23. Lundquist P, Artursson P. Oral absorption of peptides and nanoparticles across the human intestine: Opportunities, limitations and studies in human tissues. Adv Drug Deliv Rev 2016;106:256-76.

24. Golding M, Wooster TJ. The influence of emulsion structure and stability on lipid digestion. Curr Opin Coll Interface Sci 2010;15:90-101

25. Juliano R, Bauman J, Kang H, Ming X. Biological barriers to therapy with antisense and siRNA oligonucleotides. Mol Pharm 2009;6:686-95.

26. Ensign LM, Cone R, Hanes J. Oral drug delivery with polymeric nanoparticles: The gastrointestinal mucus barriers. Adv Drug Deliv Rev 2012;64:557-70.

27. Elsabahy M, Wooley KL. Design of polymeric nanoparticles for biomedical delivery applications. Chem Soc Rev 2012;41:2545-61.

28. Sosnik A, das Neves J, Sarmento B. Mucoadhesive polymers in the design of nano-drug delivery systems for administration by nonparenteral routes: A review. Prog Pol Sci 2014;39:2030-75.

29. Cha JM, Shin EK, Sung JH, Moon GJ, Kim EH, Cho YH, et al. Efficient scalable production of therapeutic microvesicles derived from human mesenchymal stem cells. Sci Rep 2018;8:1-6.

30. Pareyson D, Marchesi C. Diagnosis, natural history, and management of Charcot-Marie-Tooth disease. Lancet Neurol 2009;8:654-67.

31. Van der Zande M, Vandebriel RJ, Van Doren E, Kramer E, Herrera Rivera Z, Serrano-Rojero CS, et al. Distribution, elimination, and toxicity of silver nanoparticles and silver ions in rats after 28-day oral exposure. ACS Nano 2012;6:7427-42.

32. Bergin IL, Witzmann FA. Nanoparticle toxicity by the gastrointestinal route: Evidence and knowledge gaps. Int J Biomed Nanosci Nanotechnol 2013;3:163-210.

33. Luoma SN. Silver nanotechnologies and the environment. Project Emerg Nanotechnol Rep 2008;15:12-3

34. Wijnhoven SW, Peijnenburg WJ, Herberts CA, Hagens WI, Oomen AG, Heugens EH, et al. Nano-silver-a review of available data and knowledge gaps in human and environmental risk assessment. Nanotoxicology 2009;3:109-38.

35. Kermanizadeh A, Balharry D, Wallin H, Loft S, Møller P. Nanomaterial translocation-the biokinetics, tissue accumulation, toxicity and fate of materials in secondary organs-a review. Crit Rev Toxicol 2015:45:837-72.

36. Johnston HJ, Hutchison G, Christensen FM, Peters S, Hankin S, Stone V. A review of the in vivo and in vitro toxicity of silver and gold particulates: Particle attributes and biological mechanisms responsible for the observed toxicity. Crit Rev Toxicol 2010;40:328-46.

37. Shi H, Magaye R, Castranova V, Zhao J. Titanium dioxide nanoparticles: A review of current toxicological data. Part Fibre Toxicol 2013;10:1-33.

38. Avcu E, Baştan FE, Abdullah HZ, Rehman MA, Avcu YY, Boccaccini AR. Electrophoretic deposition of chitosan-based composite coatings for biomedical applications: A review. Prog Mater Sci 2019;103:69-108.

39. Benison E. 1 Use of sugammadex for reversal of rocuronium after emergency laparotomy in a patient with brittle myasthenia gravis. Anaesthesia 2012;67:815-9.

40. Mathur P, Jha S, Ramteke S, Jain NK. Pharmaceutical aspects of silver nanoparticles. Artific Cells Nanomed Biotechnol 2018;46:115-26.

41. Yin Y, Tan Z, Hu L, Yu S, Liu J, Jiang G. Isotope tracers to study the environmental fate and bioaccumulation of metal-containing engineered nanoparticles: Techniques and applications. Chem Rev 2017;117:4462-87.

42. More SB, Belapurkar P, Patil G, Mohan M. Toxicity by silver nanoparticles. Int J Adv Res Dev 2018;3:213-22.

43. Surendhiran D, Cui H, Lin L. Mode of transfer, toxicity and negative impacts of engineered nanoparticles on environment, human and animal health. In: The ELSI Handbook of Nanotechnology: Risk, Safety, ELSI and Commercialization. United States: Wiley-Scrivener; 2020. p. $165-204$.

44. Matysik-Woźniak A, Turski WA, Turska M, Paduch R, Łańcut M, Piwowarczyk $\mathrm{P}$, et al. Tryptophan as a safe compound in topical ophthalmic medications: In Vitro and in Vivo Studies. Ocular Immunol Inflamm 2021;:1-1.

45. Cortés C, Domenech J, Salazar M, Pastor S, Marcos R, Hernández A. Nanoplastics as a potential environmental health factor: Effects of polystyrene nanoparticles on human intestinal epithelial caco-2 cells. Environ Sci Nano 2020;7:272-85.

46. Kasendra M, Tovaglieri A, Sontheimer-Phelps A, Jalili-Firoozinezhad S, Bein A, Chalkiadaki A, et al. Development of a primary human small intestine-on-a-chip using biopsy-derived organoids. Sci Rep 2018;8:1-4.

47. Karn B, Kuiken T, Otto M. Nanotechnology and in situ remediation: A review of the benefits and potential risks. Environ Health Perspect 2009; 117:1813-31

48. Palesi F, Tournier JD, Calamante F, Muhlert N, Castellazzi G, Chard D, et al. Contralateral cerebello-thalamo-cortical pathways with prominent involvement of associative areas in humans in vivo. Brain Struct Funct 2015;220:3369-84.

49. Rashed HM, Shamma RN, Basalious EB. Contribution of both olfactory and systemic pathways for brain targeting of nimodipineloaded lipo-pluronics micelles: In vitro characterization and in vivo biodistribution study after intranasal and intravenous delivery. Drug Deliv 2017;24:181-7.

50. Silva MH. Effects of low-dose chlorpyrifos on neurobehavior and potential mechanisms: A review of studies in rodents, zebrafish, and Caenorhabditis elegans. Birth Defects Res 2020;112:445-79.

51. Verma SK, Nandi A, Sinha A, Patel P, Jha E, Mohanty S, et al. Zebrafish (Danio rerio) as an ecotoxicological model for nanomaterial induced toxicity profiling. Prec Nanomed 2021;4:750-82.

52. Ahiwale RJ, Chellampillai B, Pawar AP. Investigation of novel sorafenib tosylate loaded biomaterial based nano-cochleates dispersion system for treatment of hepatocellular carcinoma. J Dispers Sci Technol 2021;2021:1-9.

53. Zmora N, Suez J, Elinav E. You are what you eat: Diet, health and the gut microbiota. Nat Rev Gastroenterol Hepatol 2019;16:35-56.

54. Ferrando-Magraner E, Bellot-Arcís C, Paredes-Gallardo V, AlmerichSilla JM, García-Sanz V, Fernández-Alonso M. Antibacterial properties of nanoparticles in dental restorative materials. A systematic review and 
meta-analysis. Medicina 2020;56:55

55. Furxhi I, Murphy F, Mullins M, Arvanitis A, Poland CA. Nanotoxicology data for in silico tools: A literature review. Nanotoxicology 2020;14:612-37.

56. Nakamura S, Sato M, Sato Y, Ando N, Takayama T, Fujita M, et al. Synthesis and application of silver nanoparticles (Ag NPs) for the prevention of infection in healthcare workers. Int J Mol Sci 2019;20:3620.

57. Nakkala JR, Mata R, Raja K, Chandra VK, Sadras SR. Green synthesized silver nanoparticles: Catalytic dye degradation, in vitro anticancer activity and in vivo toxicity in rats. Mater Sci Eng C 2018;91:372-81.

58. Chinnappan M, Srivastava A, Amreddy N, Razaq M, Pareek V, Ahmed R, et al. Exosomes as drug delivery vehicle and contributor of resistance to anticancer drugs. Cancer Lett 2020;486:18-28.

59. Shen MH, Zhou XX, Yang XY, Chao JB, Liu R, Liu JF. Exposure medium: Key in identifying free $\mathrm{Ag}+$ as the exclusive species of silver nanoparticles with acute toxicity to Daphnia magna. Sci Rep 2015;5:1-8.

60. Milardi D, Gazit E, Radford SE, Xu Y, Gallardo RU, Caflisch A, et al. Proteostasis of islet amyloid polypeptide: A molecular perspective of risk factors and protective strategies for Type II diabetes. Chem Rev
2021;121:1845-93

61. Sangalli D, Ferretti A, Miranda H, Attaccalite C, Marri I, Cannuccia E, et al. Many-body perturbation theory calculations using the yambo code. J Phys Condensed Matter 2019;31:325902.

62. Biosca A, Bouzón-Arnáiz I, Spanos L, Siden-Kiamos I, Iglesias V, Ventura S, et al. Detection of protein aggregation in live Plasmodium parasites. Antimicrob Agents Chemother 2020;64:e2135-19.

63. Briffa SM, Nasser F, Valsami-Jones E, Lynch I. Uptake and impacts of polyvinylpyrrolidone (PVP) capped metal oxide nanoparticles on Daphnia magna: Role of core composition and acquired corona. Environ Sci Nano 2018;5:1745-56.

64. Gunaalan K, Fabbri E, Capolupo M. The hidden threat of plastic leachates: A critical review on their impacts on aquatic organisms. Water Res 2020;184:116170.

65. Geiss O, Bianchi I, Senaldi C, Bucher G, Verleysen E, Waegeneers N, et al. Particle size analysis of pristine food-grade titanium dioxide and E 171 in confectionery products: Interlaboratory testing of a singleparticle inductively coupled plasma mass spectrometry screening method and confirmation with transmission electron microscopy. Food Control 2021;120:107550. 